\title{
Throughputs of two cohorts of dental students at Sefako Makgatho Health Sciences University: A comparison
}

SADJ July 2020, Vol. 75 No. 6 p291 - p297

SR Mthethwa ${ }^{1}$, PM Nyalunga ${ }^{2}$, TS Gugushe ${ }^{3}$

\section{ABSTRACT}

\section{Introduction}

The numbers of student dentists enrolled at dental schools across the country do not give an indication of the students' progress to degree.

\section{Aims and objectives}

To describe and compare the throughputs of dentistry course for two cohorts of students at Sefako Makgatho Health Science University.

The progress to degree of the 2005 and 2010 cohorts of first year dental students was tracked and compared.

\section{Design}

A comparative cross-sectional study.

\section{Methods}

Academic records of the 2005 and 2010 cohorts of first year dental students were followed up over a fiveyear period. Data related to the demographic characteristics, numbers enrolled, numbers who dropped out, and the numbers who graduated were acquired and then captured in Microsoft Excel software.

\section{Results}

Female students constituted the majority of enrolees in both cohorts (53.8\% vs. 51.3\%). The proportions of students who started the course, completed the degree and graduated within the regulation time among the 2005 and 2010 cohorts were similar $(42.1 \%$ vs. $41.2 \%)$.

\section{Author affiliations:}

1. Sibusiso R Mthethwa: $B D S, M P H, P h D$, Sefako Makgatho Health Sciences University, South Africa. ORCID Number: 0000-0003-0420-808X

2. Phabian M Nyalunga: $B D T, B D S$, Sefako Makgatho Health Sciences University, South Africa.

3. Tshepo S Gugushe: BSc, BDS, DHSM, MDent, MPhil, Sefako Makgatho Health Sciences University, South Africa.

\section{Corresponding author: SR Mthethwa}

Medunsa Campus, PO Box D24, Sefako Makgatho Health Sciences

University 0204, South Africa.

Email: rocky.mthethwa@smu.ac.za

Author contributions:

1. Sibusiso R Mthethwa: Conception; design; acquisition of data; analysis and interpretation of data; drafting the article - 33.3\%

2. Phabian $\mathbf{M}$ Nyalunga: Conception; revising the article critically for important intellectual content - 33.3\%

3. Tshepo S Gugushe: revising the article critically for important intellectual content - $33.3 \%$
A lone student among the 2010 cohort dropped out of the course. The majority of students (57.9\% vs. 55.9\%) in both cohorts took longer to qualify.

\section{Conclusions}

The throughputs of dentistry course for the two cohorts hovered around $40 \%$.

\section{INTRODUCTION AND BACKGROUND}

There is a shortage of oral health personnel in South Africa. Oral health personnel, including dental assistants, oral hygienists, dental therapists, and dentists, have been estimated to constitute 0.2 per 1000 population. ${ }^{1}$

A meagre dental practitioner to population ratio of 1.09 per 10,000 has been estimated. ${ }^{2}$ There is currently a debate about how to alleviate this shortage. An argument has been made that we should be training fewer dentists and more oral hygienists and dental therapists. ${ }^{3}$ This line of reasoning is supported by evidence emerging from epidemiological studies of the burden of disease.

Evidence indicates that dental caries is the most prevalent oral disease ${ }^{4}$ - the latest national survey found that more than $80 \%$ of dental caries in children was untreated. ${ }^{5}$ Previously unobserved oral health priorities, which include conditions such as periodontal disease, oral manifestations of HIV/AIDS, dental trauma, oral cancer and craniofacial anomalies, are now under consideration, adding to the burden. ${ }^{6,7}$

An analysis of the throughput of the various courses offered at dental schools in the country could enrich the debate on the number and mix of oral health personnel required to provide necessary services. The results of such an investigation will be useful to policy-makers in developing human resources plan for oral health and to the dental schools' management in identifying impediments to graduation in order to offer the necessary academic and mentoring support to enable success.

The median throughput of the dental therapy courses for the period between 2004 and 2014 at Sefako Makgatho Health Sciences University has recently been established to be 45 percent with an interquartile range of 37 to 58.5 percent. ${ }^{8}$ This finding is rather disappointing. The current study seeks to describe the throughputs for two cohorts of students in the dentistry course at Sefako Makgatho Health Science University during the period between 2005 and 2014. 
The results of a recent review of Health Professions Council of South Africa (HPCSA) records indicate that the number of dentists increased at around $2 \%$ per annum during the period 2002 to $2015 .{ }^{9}$ The study revealed a welcome change in the demographic profile of dentists. It found a relatively sharp increase in the number of Coloured, Black and female registered dentists. ${ }^{9}$

The aggregate number of student dentists currently enrolled in the four dental schools in the country is $11^{158 . .^{10}}$ This figure does not give an indication of the students' progress to degree. A most recent systematic review of the literature clusters the determinants of university dropout and delayed graduation into four main categories i.e. students' characteristics, abilities and behaviour; parental background and family networks; characteristics of tertiary education system and institutions, and labour market conditions. ${ }^{11}$

The strong association of race, gender, matriculation score and poverty with dropout or graduation at South African universities is well documented. ${ }^{12,13,14}$ The association, if any, of student motivation with dropout or graduation is an important issue for future research. The results of a national survey among early-phase student dentists are extremely concerning. The survey found that for a third of respondents, dentistry was not a first choice - amongst the White students, it was a first choice for $82 \%$ compared with 59\% amongst Black Africans. ${ }^{15}$

\section{OBJECTIVES OF THE STUDY}

To describe the demographic changes undergone by the 2005 and 2010 cohorts of first year dental students in successive years of study.

To track and compare the progress to degree of the 2005 and 2010 cohorts of first year dental students. To determine the median numbers of students who completed their degree and graduated within the regulation time.

\section{MATERIALS AND METHODS}

\section{Study design}

This was a retrospective, comparative cross-sectional study in which existing academic records were reviewed.

\section{Target population}

The sampling frame consisted of academic records of a subpopulation of dental students who were enrolled at Sefako Makgatho Health Sciences University during the period 2005 to 2014 i.e. academic records of cohorts of first year dental students who were enrolled in 2005 and 2010 respectively were followed up over a five-year period.

Study sample

Every available record was studied.

\section{Data collection}

Data related to the demographic characteristics of the students, the numbers enrolled, numbers who dropped out, and the numbers who graduated were acquired and then captured in Microsoft Excel software.

\section{Definition of variables and terms}

Age and gender refer to student age and sex as recorded in the academic records.

Population group breakdown of students into African, Indian, Coloured and White will be applied according to the Population Registration Act of $1950 .{ }^{16}$

Progress to degree refers to enrolment and academic progress.

Regulation time is the period of time normally expected for completion of the degree (five years).

Throughput, quite simply, is how many students who started studying complete the course of study. This may also be measured by the number of students who do not drop out. ${ }^{17}$ It is also referred to as the completion rate, or graduation rate. ${ }^{18}$

First-timer refers to a student who was enrolled in a year of study for the first time.

\section{Ethical considerations}

Ethical approval for the study was granted by the Ethics Committee of Sefako Makgatho Health Sciences University (SMREC/D/1820/2017). Permission to conduct the study was granted by the Chief Executive Officer (CEO) of the Medunsa Oral Health Centre.

\section{STATISTICAL ANALYSIS/ HYPOTHESIS TESTING}

Collected data were subjected to univariate and bivariate analysis in Statistical Package for the Social Sciences (SPSS) software. Frequencies, means and proportions were calculated. Chi-square tests were performed to test the statistical significance of the differences in proportions. Chi-square tests for trends were performed to investigate trends in enrolments and examination pass rates. The chosen significance level of the tests was a $\mathrm{p}$-value less than 0.05 .

\section{RESULTS}

Academic records of the 2005 and 2010 cohorts of first year dental students were followed up over a five-year period and analysed.

The total number of enrollees followed up over the five years of study in the 2005 cohort was $10.4 \%$ more than that of the 2010 cohort. The first year class of the 2005 cohort was $28.9 \%$ larger than that of the 2010 cohort.

On the one hand, the fifth year class of the 2005 cohort was $26.9 \%$ smaller than the first year class. On the other hand, the fifth year class of the 2010 cohort was $27 \%$ larger than the first year class. Female students constituted the majority (54.5\%) of the enrollees - they were the majority in all classes of the 2005 cohort. 


\begin{tabular}{|c|c|c|c|c|c|c|c|}
\hline \multirow[t]{2}{*}{ Cohort } & \multirow[t]{2}{*}{ Gender } & \multicolumn{5}{|c|}{ Year of study } & \multirow{2}{*}{$\begin{array}{l}\text { Total } \\
\mathrm{n}(\%)\end{array}$} \\
\hline & & First n (\%) & Second $\mathrm{n}(\%)$ & Third n (\%) & Fourth n (\%) & Fifth n (\%) & \\
\hline \multirow[t]{3}{*}{2005} & Male & $24(46.2)$ & $22(41.5)$ & $23(44.2)$ & $18(40)$ & 15 (39.5) & $102(42.5)$ \\
\hline & Female & $28(53.8)$ & $31(58.5)$ & $29(55.8)$ & $27(60)$ & $23(60.5)$ & $138(57.5)$ \\
\hline & Total & $52(100)$ & $53(100)$ & $52(100)$ & $45(100)$ & $38(100)$ & $240(100)$ \\
\hline \multirow[t]{3}{*}{2010} & Male & $18(48.7)$ & $22(51.2)$ & 20 (51.3) & 23 (46.9) & $22(46.8)$ & $105(48.8)$ \\
\hline & Female & 19 (51.3) & $21(48.8)$ & $19(48.7)$ & $26(53.1)$ & 25 (53.2) & $110(51.2)$ \\
\hline & Total & $37(100)$ & $43(100)$ & $39(100)$ & $49(100)$ & 47 (100) & $215(100)$ \\
\hline \multirow[t]{3}{*}{ Total } & Male & $42(47.2)$ & $44(45.8)$ & $43(47.3)$ & $41(43.6)$ & 37 (43.5) & 207 (45.5) \\
\hline & Female & $47(52.8)$ & $52(54.2)$ & $48(52.7)$ & $53(56.4)$ & $48(56.5)$ & $248(54.5)$ \\
\hline & Total & $89(100)$ & $96(100)$ & $91(100)$ & $94(100)$ & $85(100)$ & $455(100)$ \\
\hline \multirow[t]{2}{*}{ Cohort } & Race & \multicolumn{5}{|c|}{ Year of study } & Total \\
\hline & & First n (\%) & Second $n(\%)$ & Third n (\%) & Fourth n (\%) & Fifth $n(\%)$ & n (\%) \\
\hline \multirow[t]{4}{*}{2005} & African & 44 (84.6) & 45 (84.9) & $46(88.5)$ & 40 (88.9) & 32 (84.2) & 207 86.3) \\
\hline & Indian & $5(9.6)$ & $5(9.4)$ & $4(7.7)$ & $3(6.7)$ & $4(10.5)$ & $21(8.8)$ \\
\hline & White & $3(5.8)$ & $3(5.7)$ & $2(3.8)$ & $2(4.4)$ & $2(5.3)$ & $12(4.9)$ \\
\hline & Total & $52(100)$ & $53(100)$ & $52(100)$ & 45 (100) & $38(100)$ & $240(100)$ \\
\hline \multirow[t]{4}{*}{2010} & African & $27(73.0)$ & $32(74.4)$ & $36(92.3)$ & $46(93.9)$ & $43(91.5)$ & $184(85.6)$ \\
\hline & Indian & $4(10.8)$ & 5 (11.6) & $1(2.6)$ & $1(2.0)$ & $2(4.3)$ & $13(6.1)$ \\
\hline & White & $6(16.2)$ & $6(14)$ & $2(5.1)$ & $2(4.1)$ & $2(4.2)$ & 18 (8.3) \\
\hline & Total & $37(100)$ & $43(100)$ & $39(100)$ & $49(100)$ & 47 (100) & 215 (100) \\
\hline \multirow[t]{4}{*}{ Total } & African & $71(79.8)$ & 77 (80.2) & $82(90.1)$ & $86(91.5)$ & 75 (88.2) & 391 (85.9) \\
\hline & Indian & $9(10.1)$ & $10(10.4)$ & $5(5.5)$ & $4(4.25)$ & $6(7.1)$ & $34(7.5)$ \\
\hline & White & $9(10.1)$ & $9(9.4)$ & $4(4.4)$ & $4(4.25)$ & $4(4.7)$ & $30(6.6)$ \\
\hline & Total & $89(100)$ & 96 (100) & $91(100)$ & $94(100)$ & $85(100)$ & 455 (100) \\
\hline \multirow[t]{2}{*}{ Cohort } & First-timer & \multicolumn{5}{|c|}{ Year of study } & Total \\
\hline & & First n (\%) & Second n (\%) & Third n (\%) & Fourth n (\%) & Fifth $n(\%)$ & n (\%) \\
\hline \multirow[t]{3}{*}{2005} & No & $14(26.9)$ & 10 (18.9) & 7 (13.5) & $5(11.1)$ & $2(5.3)$ & $38(15.8)$ \\
\hline & Yes & $38(73.1)$ & $43(81.1)$ & 45 (86.5) & 40 (88.9) & $36(94.7)$ & $202(84.2)$ \\
\hline & Total & $52(100)$ & $53(100)$ & $52(100)$ & $45(100)$ & $38(100)$ & $240(100)$ \\
\hline \multirow[t]{3}{*}{2010} & No & $3(8.1)$ & $10(23.3)$ & $8(20.5)$ & $23(46.9)$ & $5(10.6)$ & $49(22.8)$ \\
\hline & Yes & 34 (91.9) & $33(76.7)$ & $31(79.5)$ & $26(53.1)$ & $42(89.4)$ & $166(77.2)$ \\
\hline & Total & $37(100)$ & $43(100)$ & $39(100)$ & $49(100)$ & $47(100)$ & $215(100)$ \\
\hline \multirow[t]{3}{*}{ Total } & No & $17(19.1)$ & $20(20.8)$ & $15(16.5)$ & $28(29.8)$ & $7(8.2)$ & $87(19.1)$ \\
\hline & Yes & 72 (80.9) & $76(79.2)$ & $76(83.5)$ & $66(70.2)$ & 78 (91.8) & 368 (80.9) \\
\hline & Total & 89 (100) & $96(100)$ & $91(100)$ & $94(100)$ & $85(100)$ & 455 (100) \\
\hline
\end{tabular}

\begin{tabular}{|c|c|c|c|c|c|}
\hline \multirow[t]{2}{*}{ Cohort } & \multirow[t]{2}{*}{ Year of study } & \multicolumn{2}{|c|}{ Examination Results } & \multirow{2}{*}{$\begin{array}{l}\text { Total } \\
\text { n (\%) }\end{array}$} & \multirow[t]{2}{*}{ Chi-squared test for trend } \\
\hline & & Pass n (\%) & Fail n (\%) & & \\
\hline \multirow[t]{6}{*}{2005} & First & $43(82.7)$ & $9(17.3)$ & $52(100)$ & \\
\hline & Second & $48(90.6)$ & $4(9.4)^{\star}$ & $53(100)$ & \\
\hline & Third & $41(78.8)$ & $11(21.2)$ & $52(100)$ & $p=0.254$ \\
\hline & Fourth & $36(80)$ & $920)$ & $45(100)$ & \\
\hline & Fifth & $26(68.4)$ & $12(31.6)$ & $38(100)$ & \\
\hline & Total & $194(80.8)$ & $45(19.2)^{*}$ & $240(100)$ & \\
\hline \multirow[t]{6}{*}{2010} & First & 34 (91.9) & $3(8.1)$ & $37(100)$ & \\
\hline & Second & $31(72.1)$ & $11(27.9)^{\star}$ & $43(100)$ & \\
\hline & Third & $26(66.7)$ & $12(33.3)^{\star}$ & $39(100)$ & $p=0.254$ \\
\hline & Fourth & $42(85.7)$ & $6(14.3)^{\star}$ & 49 (100) & \\
\hline & Fifth & $47(100)$ & $0(0)$ & $47(100)$ & \\
\hline & Total & $180(83.7)$ & $32(16.3)^{\star \star \star}$ & $215(100)$ & \\
\hline \multirow[t]{6}{*}{ Total } & First & 77 (86.5) & $12(13.5)$ & $89(100)$ & \\
\hline & Second & 79 (82.3) & $15(17.7)^{\star \star}$ & $96(100)$ & \\
\hline & Third & $67(73.6)$ & $23(26.4)^{\star}$ & 91 (100) & $p=0.254$ \\
\hline & Fourth & 78 (83.0) & $15(17)^{\star}$ & $94(100)$ & \\
\hline & Fifth & 73 (85.9) & $12(14.1)$ & 85 (100) & \\
\hline & Total & 374 (82.2) & $77(17.8)^{\star \star \star \star}$ & 455 (100) & \\
\hline
\end{tabular}




\begin{tabular}{|c|c|c|c|c|c|c|c|c|}
\hline \multirow{2}{*}{ Cohorts } & \multicolumn{5}{|c|}{ Year of study } & \multirow{2}{*}{$\begin{array}{l}\text { Number of } \\
\text { graduates }\end{array}$} & \multirow{2}{*}{ Throughput (\%) } & \multirow{2}{*}{ Chi-squared tes } \\
\hline & First & Second & Third & Fourth & Fifth & & & \\
\hline 2005 & 38 & 29 & 27 & 20 & 16 & 16 & 42.1 & $p=0.937$ \\
\hline 2010 & 34 & 30 (1) & 20 & 16 & 14 & 14 & 41.2 & \\
\hline
\end{tabular}

\begin{tabular}{|c|c|c|c|c|c|c|c|c|}
\hline \multirow{2}{*}{ Cohorts } & \multicolumn{5}{|c|}{ Year of study } & \multirow{2}{*}{$\begin{array}{l}\text { Number of } \\
\text { graduates }\end{array}$} & \multirow{2}{*}{ Throughput (\%) } & \multirow{2}{*}{ Chi-squared tes } \\
\hline & First & Second & Third & Fourth & Fifth & & & \\
\hline 2005 & 22 & 19 & 18 & 13 & 9 & 9 & 40.9 & $p=0.454$ \\
\hline 2010 & 23 & 21 & 14 & 12 & 12 & 12 & 52.2 & \\
\hline
\end{tabular}

\begin{tabular}{|c|c|c|c|c|c|c|c|c|}
\hline \multirow{2}{*}{ Cohorts } & \multicolumn{5}{|c|}{ Year of study } & \multirow{2}{*}{$\begin{array}{l}\text { Number of } \\
\text { graduates }\end{array}$} & \multirow{2}{*}{ Throughput (\%) } & \multirow{2}{*}{ Chi-squared tes } \\
\hline & First & Second & Third & Fourth & Fifth & & & \\
\hline 2005 & 16 & 10 & 9 & 7 & 7 & 7 & 43.8 & $p=0.174$ \\
\hline 2010 & 11 & 9 & 6 & 4 & 2 & 2 & 18.2 & \\
\hline
\end{tabular}

\begin{tabular}{|c|c|c|c|c|}
\hline \multirow{2}{*}{$\begin{array}{l}\text { Tertiary } \\
\text { education }\end{array}$} & \multicolumn{2}{|c|}{ Graduated } & \multirow{2}{*}{ Total } & \multirow{2}{*}{ Chi-squared test } \\
\hline & Yes n (\%) & No n (\%) & & \\
\hline Present & $9(40.91)$ & 13 (59.09) & $22(100)$ & $p=0.862$ \\
\hline Absent & 7 (43.75) & $9(56.25)$ & $16(100)$ & \\
\hline Total & $16(42.11)$ & $22(57.89)$ & $38(100)$ & \\
\hline
\end{tabular}

\begin{tabular}{|c|c|c|c|c|}
\hline \multirow{2}{*}{$\begin{array}{l}\text { Tertiary } \\
\text { education }\end{array}$} & \multicolumn{2}{|c|}{ Graduated } & \multirow{2}{*}{ Total } & \multirow{2}{*}{ Chi-squared test } \\
\hline & Yes n (\%) & No n (\%) & & \\
\hline Present & $12(52.17)$ & $11(47.83)$ & $23(100)$ & $p=0.063$ \\
\hline Absent & $2(18.8)$ & $9(81.82)$ & $11(100)$ & \\
\hline Total & $14(41.18)$ & $20(58.82)$ & $34(100)$ & \\
\hline
\end{tabular}

In contrast, they were in the minority in the second and third year classes of the 2010 cohort.

African students constituted a vast majority (85.9\%) of the enrolees - they were an overwhelming majority in all classes of both cohorts. Indian students comprised the second largest racial group of enrolees at a mere $7.5 \%$.

A marginal (3.4\%) increase in the proportion of White students was observed between the 2005 and 2010 cohorts.

One out of five $(19.1 \%)$ enrolee was a repeater - they comprised $15.8 \%$ and $22.8 \%$ of the 2005 and 2010 cohorts respectively.

One out of four (26.9\%) enrolee in the first year class of the 2005 cohort was a repeater compared with less than ten percent $(8.1 \%)$ in the first year class of the of the 2010 cohort. Almost half (46.9\%) of the fourth year class in the 2010 cohort were repeaters.

A steady decline in the proportion of repeaters was observed among the 2005 cohort from the first to fifth years of study.

The mean examination pass rate of the 2010 cohort was slightly higher $(83.7 \%$ vs $80.8 \%)$ than that of the 2005 cohort. The difference was however not statistically significant $(p>0.05)$.
A two-thirds examination pass rate was the lowest rate achieved by both cohorts - $68.4 \%$ was recorded in the fifth year class of the 2005 cohort compared with $66.7 \%$ in the third year class of the 2010 cohort.

Three students, who failed the examinations, dropped out of the course among the 2010 cohort compared with one student among the 2005 cohort.

There was insufficient evidence to reject the null hypothesis of no trend in the proportion of students who passed the examination in the population ( $p>0.05)$ for both cohorts.

The proportions of students who started the course in 2005 and 2010 and completed the degree in 2009 and 2014 and graduated in 2010 and 2015 within the regulation time was similar (42.1\% vs $41.2 \%)$. A lone student among the 2010 cohort dropped out of the course. The majority of students $(57.9 \%$ vs. $55.9 \%)$ of both cohorts took longer to qualify.

Eleven percent more first-timers with tertiary education among the 2010 cohort compared with the 2005 cohort completed the degree and graduated within the regulation time. The difference in proportions was however not statistically significant ( $p>0.05) .59 .1 \%(13 / 22)$ of students in the 2005 cohorts took longer to qualify. Twenty-five percent more first-timers without tertiary education among the 2005 cohort compared with the 2010 
cohort completed the degree and graduated within the regulation time. The difference in proportions was however not statistically significant ( $p>0.05)$. 82\% (9/11) of students in the 2010 cohorts took longer to qualify.

Slightly (2.84\%) more students without tertiary education graduated within the regulation time than those with tertiary qualification. There was insufficient evidence ( $p>0.05)$ to reject the null hypothesis that the proportions of students that graduated were equal in the two groups in the population.

A little less than three times (2.78 times) as many students with tertiary education graduated within the regulation time as were those without tertiary education. There was however insufficient evidence $(p>0.05)$ to reject the null hypothesis that the proportions of students that graduated were equal in the two groups in the population.

\section{DISCUSSION}

This study set out to track, over a five-year period, and compare the progress to degree of first year dental students who were enrolled in 2005 and 2010.

The number of students who completed their degree and graduated within the stipulated time was also determined.

\section{Demographic characteristics}

The current study found that the size of the 2005 cohort was 28.9\% larger than that of the 2010 cohort in the first year of study (Table 1). This unanticipated discrepancy coincided with the founding of the University of Limpopo (MEDUNSA Campus), a predecessor of Sefako Makgatho Health Sciences University. It may be due to institutional inexperience.

The results of this study indicate that female students constituted the majority (54.5\%) of the enrolees of both cohorts (Table 1). The present findings seem to be consistent with other research which found that female students constitute the majority of dental students. ${ }^{15}$ The most interesting finding was that the variation in numbers of enrolees between the first and fifth year classes of both cohorts was in different directions yet similar i.e. a $26.9 \%$ decline among the 2005 cohort in contrast to the $27.0 \%$ rise among the 2010 cohort (Table 1). This rather contradictory result was due to the significant difference $(31.6 \%)$ in the examination pass rates between the fifth year classes of the 2005 and 2010 cohorts.

The results of this study show that African students constituted an overwhelming majority (85.9\%) of the enrolees (Table 2). This foreseeable finding is inextricably linked with the founding mission of the predecessor institutions.

Medunsa, the Medical University of Southern Africa, was founded in 1976 to address both the under-representation of blacks in the health professions and the lack of good health care in the homelands. The university trains most of the black physicians, dentists, veterina- rians, and allied health professionals in South Africa. ${ }^{19}$ The results of this study show a significant reduction in the proportion of first year repeaters from a high of $26.9 \%$ in the 2005 cohort to a low of $8.1 \%$ in the 2010 cohort (Table 3 ). This encouraging finding suggests that the academic and mentoring support offered is effective.

In contrast, the current study found that repeaters constituted a strikingly large size (46.9\%) of the fourth year class of the 2010 cohort. The observed significant increase in the number of repeaters in the fourth year class of 2013 could be attributed to fact that the large class size (59 students) of the previous year consisted of a relatively large number of weak students. Further research is required to establish the major factors that cause students to repeat a class.

\section{Demographic characteristics}

The current study found that the size of the 2005 cohort was $28.9 \%$ larger than that of the 2010 cohort in the first year of study (Table 1). This unanticipated discrepancy coincided with the founding of the Sefako Makgatho Health Sciences University. It may be due to institutional inexperience.

The results of this study indicate that female students constituted the majority (54.5\%) of the enrolees of both cohorts (Table 1). The present findings seem to be consistent with other research which found that female students constitute the majority of dental students. ${ }^{15}$ The most interesting finding was that the variation in numbers of enrolees between the first and fifth year classes of both cohorts was in different directions yet similar i.e. a $26.9 \%$ decline among the 2005 cohort in contrast to the $27.0 \%$ rise among the 2010 cohort (Table 1). This rather contradictory result was due to the significant difference $(31.6 \%)$ in the examination pass rates between the fifth year classes of the 2005 and 2010 cohorts.

The results of this study show that African students constituted an overwhelming majority (85.9\%) of the enrolees (Table 2). This foreseeable finding is inextricably linked with the founding mission of the predecessor institutions. Medunsa, the Medical University of Southern Africa, was founded in 1976 to address both the under-representation of blacks in the health professions and the lack of good health care in the homelands. The university trains most of the black physicians, dentists, veterinarians, and allied health professionals in South Africa. ${ }^{19}$

The results of this study show a significant reduction in the proportion of first year repeaters from a high of $26.9 \%$ in the 2005 cohort to a low of $8.1 \%$ in the 2010 cohort (Table 3 ). This encouraging finding suggests that the academic and mentoring support offered is effective.

In contrast, the current study found that repeaters constituted a strikingly large size (46.9\%) of the fourth year class of the 2010 cohort. The observed significant increase in the number of repeaters in the fourth year class of 2013 could be attributed to fact that the large class size (59 students) of the previous year consisted of 
a relatively large number of weak students. Further research is required to establish the major factors that cause students to repeat a class.

\section{Examination pass rate}

The results of this study did not show any trend in the examination pass rates (Table 4). It seems possible that these results are due to the highly variable pass rates - the pass rates ranged between $68.4 \%$ and $90.6 \%$ and between $66.7 \%$ and $100 \%$ for the 2005 and 2010 cohorts respectively.

It is however encouraging that the lowest examination pass rates were attained in different classes i.e. the fifth year class of the 2005 cohort and the third year class of the 2010 cohort respectively. These findings suggest that the lowest examination pass rates were random.

\section{Throughput}

The current study found that the throughputs of the dentistry course at Sefako Makgatho Health Sciences University (SMU) hovered around 40\% (Table 5).

Local studies of comparable cohorts were not found - the through-put of dentistry courses in the four dental schools in South Africa, namely the University of the Western Cape (UWC), University of the Witwatersrand (Wits), Sefako Makgatho Health Sciences University (SMU) and University of Pretoria (UP) has not previously been described.

The findings of the current study differ greatly from the Ministry of Education's target of $20 \%$ graduation rate for a 4 -year or more undergraduate degree..$^{20}$ However, they are broadly consistent with other research.

The Council for Higher Education (CHE) found that the regulation time throughput, for four year degrees, of cohorts of first year students enrolled in the years 2007, 2008, and 2009 ranged between $29 \%$ and $42 \% .{ }^{21}$

Furthermore, a regulation time throughput of $36.9 \%$ among first year students enrolled in 2009 has been found by researchers of the Stellenbosch University working paper. ${ }^{22}$ The throughput of the dentistry course beyond regulation time is an important issue for future research.

The results of this study indicate that prior exposure of first-timers to tertiary education did not significantly ( $p>0.05$ ) improve throughput (Tables 6, 8 and 9). This finding was unexpected. However, with a small sample size, caution must be applied in interpreting these findings.

The results of this study indicate that a lone student among the 2010 cohort dropped out of the course (Table 5). The findings of the current study do not support the previous research - the dropout rate is much lower $(2.9 \%)$ than previously reported. The Council for Higher Education (CHE) found that the dropout rate ranged between 30\% and 33\%. ${ }^{21}$ The Stellenbosch University working paper reported a dropout rate of $28.4 \% .{ }^{22}$

\section{Limitations of the study}

Data on age of the students was not available.

The determinants of university dropout and delayed graduation could not be identified as data was not available.

\section{CONCLUSION}

The throughputs of dentistry course for the two cohorts hovered around $40 \%$.

\section{References}

1. World Health Organization. Dentistry personnel density (per 1000 population) Retrieved from http://data.un.org/Data. aspx?q=dentistry\&d=WHO\&f=MEASURCODE\%3AHRH_28 [Accessed 04/07/2018].

2. Department of Health. HRH Strategy for the Health Sector: 2012/13 - 2016/17 Retrieved from http://www.hst.org.za/ publications/NonHST\%20Publications/hrh_strategy-2.pdf [Accessed 04/07/2018].

3. Bhayat A, Chikte U. Human Resources for Oral Health Care in South Africa: A 2018 Update. Int J Environ Res. Public Health 2019; 16: 1668; doi:10.3390/ijerph16101668.

4. Department of Health. National Oral Health Survey: South Africa 1988/89. Pretoria: Government Printer; 1994.

5. van Wyk P, van Wyk C. Oral health in South Africa. Int Dent J. 2004 Dec; 54(6 Suppl 1): 373-7.

6. Petersen PE. Priorities for research for oral health in the $21^{\text {st }}$ Century - the approach of the WHO Global Oral Health Programme. Community Dental Health 2005; 22: 71-4.

7. Department of Health. South African Oral Health Strategy. Retrieved from www.health.gov.za/.../strategic.../130-sd2005?...south-african-national-oral-health-stra.[Accessed 04/07/2018].

8. Masetla MM, Mthethwa SR. Dental Therapy Student cohorts: Trends in enrolment and progress at a South African University. SADJ. 2018; 73(6): 406-10.

9. Bhayat $A$, Chikte U. The changing demographic profile of dentists and dental specialists in South Africa: 2002-2015. Int Dent J. 2018; 68(2): 91-6.

10. Statistics - HPCSA. Retrieved from www.hpcsa.co.za/Publications/Statistics [Accessed 28/06/2019]

11. Aina C, Baici E, Casalone G, Pastore F. The economics of university dropouts and delayed graduation: a survey. March 2018. IZA DP No. 11421. Retrieved from http://ftp.iza.org/ dp11421.pdf Accessed [23/05/2019].

12. Council on Higher Education (CHE). A proposal for undergraduate curriculum reform in South Africa: The case for a flexible curriculum structure. Pretoria: CHE. 2013.

13. Letseka M, Maile S. High university dropout rates: A threat to South Africa's future. Pretoria: Human Science Research Council 2008.

14. Fiske EB, Ladd HF. Elusive equity: Education reform in post-apartheid South Africa. Washington, D.C: Brookings Institution Press 2004.

15. Lalloo R, Ayo-Yusuf OA, Yengopal V. Early-phase dental students' motivations and expectations concerning the study and profession of dentistry. SADJ. 2008; 63(4): 216-20.

16. Union of South Africa (1950). Popúlation Registration Act, No. 30 of 1950, in SA Government Gazette 1950.

17. van Broekhuizen H. In: FACTSHEET: How many South African students graduate? December 2016. Available https: //africacheck.org/factsheets/factsheet-many-south-africanstudents-graduate/ [Accessed 04/07/2018].

18. Jeynes K. In: FACTSHEET: How many South African students graduate? December 2016. Available https://africacheck.org/factsheets/factsheet-many-south-african-students-graduate/ [Accessed 04/07/2018]. 
19. Haynes MA, Lee AB. Medunsa and the training of black doctors for South Africa. Acad Med. 1995 Feb; 70(2): 115-21.

20. Ministry of Education. National Plan for Higher Education in South Africa. Retrieved from http:/www.justice.gov.za/commissions/FeesHET/docs/2001-NationalPlanForHigher Education.pdf [Accessed 04/07/2018].

21. Council on Higher Education. Vital Stats Public Higher Education 2014. Pretoria: CHE; 2016. Retrieved from https: //www.che.ac.za/sites/default/files/publications/Vital Stats2014\%20-\%20webversion.pdf [Accessed 04/07/2018].

22. Van Broekhuizen $\mathrm{H}$, van der Berg S, Hofmeyr $\mathrm{H}$. Higher Education Access and Outcomes for the 2008 National Matric Cohort. Stellenbosch Economic Working Papers: 16/16. 2016. Retrieved from https:/resepsun.ac.za/wp-content/uploads/2016/10/Nan-Broekhuizen-et-al.pdf [Accessed 04/07/2018].

\section{Do the CPD questionnaire on page 339}

The Continuous Professional Development (CPD) section provides for twenty general questions and five ethics questions. The section provides members with a valuable source of CPD points whilst also achieving the objective of CPD, to assure continuing education. The importance of continuing professional development should not be underestimated, it is a career-long obligation for practicing professionals.

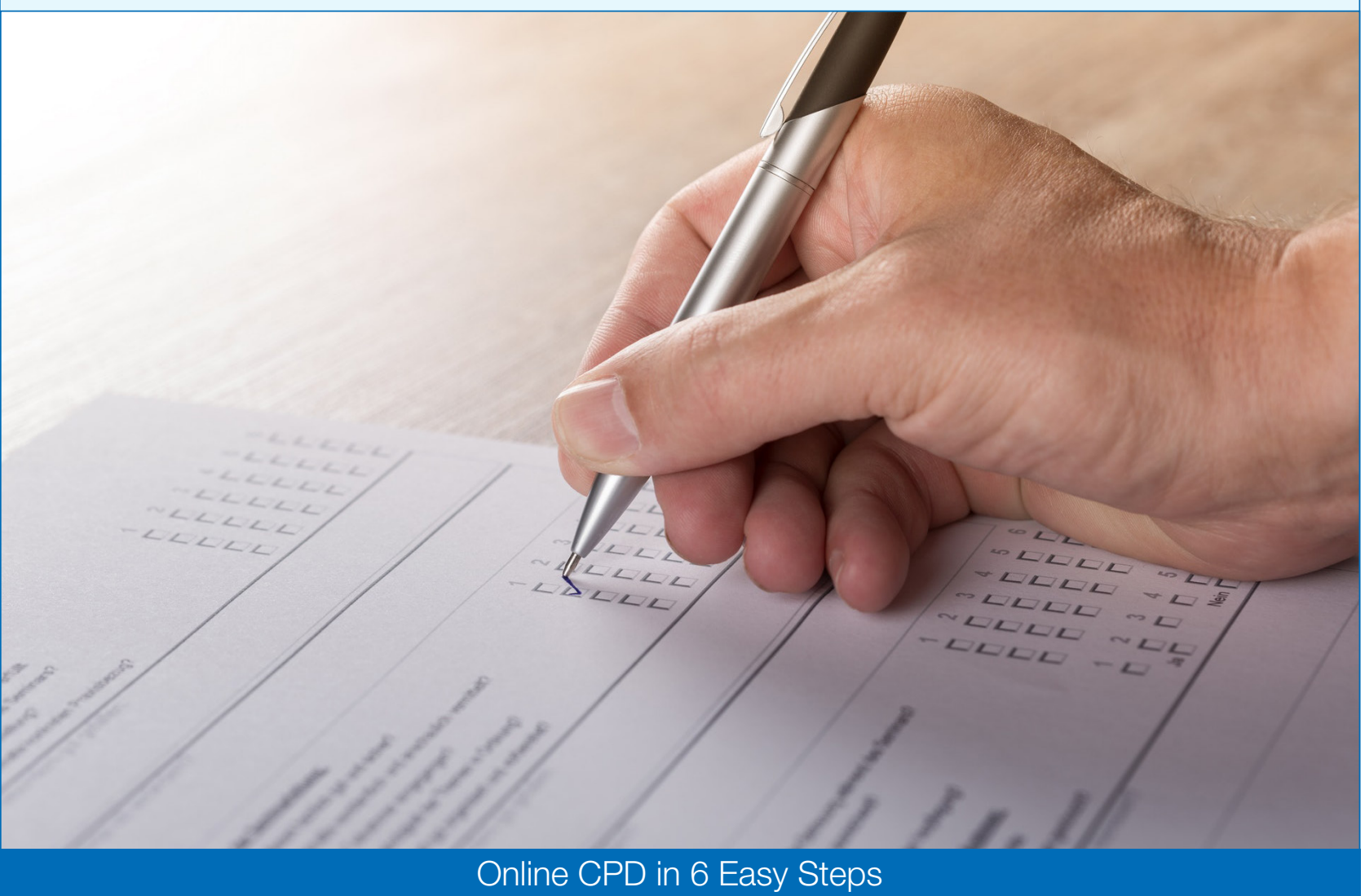

1 Go to the SADA website www.sada.co.za.

2 Log into the 'member only' section with your unique SADA username and password.

3 Select the CPD navigation tab.

4 Select the questionnaire that you wish to complete.

5 Enter your multiple choice answers. Please note that you have two attempts to obtain at least $70 \%$.

6 View and print your CPD certificate. 